\title{
Bladder cancer trends and mortality in the brazilian public health system
}

\author{
Frederico Timoteo ${ }^{1}$, Fernando Korkes ${ }^{1,2}$, Willy Baccaglini ${ }^{1}$, Sidney Glina ${ }^{1}$ \\ ${ }^{1}$ Disciplina de Urologia, Faculdade de Medicina do ABC, Santo André, SP, Brasil; ${ }^{2}$ Divisão de Urologia, \\ Hospital Israelita Albert Einstein, São Paulo, SP, Brasil
}

\section{ABSTRACT}

Introduction: Considering the lack of data on $\mathrm{BC}$ trends in Brazilian population, mainly as a result of the difficulty on gathering data, the present manuscript provides an overview of bladder cancer incidence, hospitalization, mortality patterns and trends using the Brazilian Data Center for The Public Health System (DATASUS).

Materials and Methods: All hospital admissions associated with BC diagnosis (ICD-10 C67) between 2008 and 2017 were analyzed. Distributions according to year, gender, age group, ethnicity, death, length of hospital stay, and costs were evaluated. Demographic data was obtained from the last Brazilian national census.

Results: From 2008 to 2017 there were 119,058 public hospital admissions related to BC. Patients were mostly white males aged 60 to 79 years-old. Mortality rates for patients who have undergone surgery was $6.75 \%$ on average, being $7.38 \%$ for women and $6.49 \%$ for men. Mortality rates were higher when open surgeries were performed compared to endoscopic procedures (4.98\% vs 1.18\%). Considering only endoscopic procedures, mortality rates were three times higher after urgent surgeries compared to elective ones $(2.6 \%$ vs $0.6 \%)$. Over the years the cystectomy/transurethral bladder resection $(\mathrm{C} / \mathrm{T})$ ratio significantly decreased in all Brazilian Regions. In 2008, the $\mathrm{C} / \mathrm{T}$ ratio was 0.19 , while in 2017 it reduced to 0.08 .

Conclusions: Despite BC relatively low incidence, it still represents a significant social economic burden in Brazil, as it presents with recurrent episodes that might require multiple hospitalizations and surgical treatment. The set of data collected might suggest that population access to health care has improved between 2008-2017.

\section{ARTICLE INFO}

Frederico Timoteo

http://orcid.org/0000-0002-0731-3734

\author{
Keywords: \\ Urinary Bladder Neoplasms; \\ Mortality; Public Health
}

Int Braz J Urol. 2020; 46: 224-33

Submitted for publication:

March 26, 2019

Accepted after revision:

August 30, 2019

Published as Ahead of Print:

December 23, 2019

\section{INTRODUCTION}

According to American Cancer Society, in the United States in 2018, approximately 81, 190 patients were diagnosed and about 17.240 deaths occurred due to bladder neoplasm (1). Data retrieved from the Surveillance, Epidemiology and End Results Program from National Cancer Institute (SEER), recollects that rates for new bladder cancer (BC) cases have been falling on average
$1.0 \%$ each year over the last 10 years. Nevertheless, $\mathrm{BC}$ remains as the $6^{\text {th }}$ more common type of cancer in the United States, accounting for 4.7\% of all new cancer cases (2).

Worldwide, about 549.393 new diagnosis were made and 199.922 deaths were attributed to BC in 2018, which corresponds, respectively, to $3 \%$ of all cancer diagnosis and $2.1 \%$ of cancer-related deaths (3). In Brazil, where BC figures as the seventh most common malignancy in men 
and the $14^{\text {th }}$ in women, it is estimated a yearly diagnosis of 6.43 new cases per 100.000 men and 2.63 per 100.000 women (4). Whilst more frequent in men, BC tend to be found more clinically significant and in more advanced stages in women (5). As BC manifests primarily with gross or microscopic hematuria and has a recurrent pattern, patients who have been diagnosed with the disease frequently require multiple procedures and hospitalizations, both elective or urgent, in order to achieve either cure or at least control the disease. Despite having a relatively low incidence, clinical characteristics of this neoplasms results in a relevant social and economic burden to Brazilian government. In 2014 alone, 27.738 life years were lost due to BC deaths, US\$29.879.165 were directly spent with BC treatment and an indirect loss of US\$76.996.523 was estimated (6).

It is well known that the incidence of $\mathrm{BC}$ varies geographically with higher incidence rates in Western Europe and North America and lowest rates in Eastern Europe and Asia (7). There is data recollecting that the disease incidence may vary significantly even within a country, in the United States there are lower incidence rates in Utah and Hawaii compared to the Northeastern states (8). Studies assessing mortality and incidence of BC found that more than $60 \%$ of cases and over half of the deaths occur in less developed countries (3).

Bladder cancer occurrence is strongly related to environmental factors and aging. Smokers are 2-4 times more likely to develop $\mathrm{BC}$ and this association seems to be related to smoking intensity $(9,10)$.

Workplace exposure to carcinogens may account to approximately $10-20 \%$ of BC cases (11).

Metal workers, painters, rubber industry and textile workers and cement or mine workers are professionals with higher risk for $B C$ due to exposure to polycyclic aromatic hydrocarbons $(12,13)$.

Considering social and demographic characteristics along with $\mathrm{BC}$ treatment impact on Brazilian Public Health System, it is imperative that caregivers be aware of BC epidemiology in the Brazilian population. The present manus- cript provides an overview of BC incidence, hospitalization, mortality patterns and trends using the Brazilian Data Center for The Public Health System (DATASUS).

\section{MATERIALS AND METHODS}

Brazilian Public Health System Information Database was used as the primary data source for our study. DATASUS represents the primary effort of Brazilian Federal Government to collect data from the national health system. This database includes information from all public health hospitals throughout the country, guaranteeing health support to about 170 million Brazilians.

All hospital admissions associated with BC diagnosis (ICD-10 C67) between 2008 and 2017 were analyzed. Distributions according to year, gender, age group, ethnicity, death, length of hospital stay and costs were evaluated.

Additionally, another search was performed according to surgical procedure. All procedures directly associated with BC surgery were evaluated, and divided into endoscopic surgery (codes: 0409010383-BLADDER TUMOR ENDOSCOPIC RESSECTION, 0416010172-ONCOLOGIC BLADDER TUMOR ENDOSCOPIC RESSECTION) and open surgery (codes: 0409010022-PARTIAL CYSTECTOMY, 0409010030-RADICAL CYSTECTOMY, 0409010049-SINGLE STAGE RADICAL CYSTECTOMY AND URINARY DIVERSION, 0409010057-CYSTOENTEROPLASTY, 0416010024-ONCOLOGIC SINGLE STAGE RADICAL CYSTECTOMY AND URINARY DIVERSION, 0416010032-ONCOLOGIC RADICAL CYSTECTOMY AND SIMPLE URINARY DIVERSION). For this second search, data evaluated included year, geographic region of Brazil, death rate, length of hospital stay and characteristic of hospital admission (elective vs. urgent).

Demographic data from the Brazilian population during the studied period were obtained from the last national census, realized in 2010 and trends in the rate of $\mathrm{BC}$ diagnosis and treatment from 2008 to 2017 were described.

Statistical analysis was performed using SPSS 13.0 (SPSS for Mac OS X, SPSS, Inc., Chicago, Illinois). Groups were compared with Pearson's 
chi-square test and ANOVA. Statistical significance was determined at $\mathrm{p}<0.05$.

\section{RESULTS}

From 2008 to 2017, the population that relies on Brazilian Public Health System has increased 6.3\% reaching 162 million people in 2017 and there were 119.058 patients admitted to public hospitals in Brazil with diagnosis of BC along those years. The number of hospital admissions related to BC went from 7.277 in 2008 to 16.547 in 2017. Patients admitted with BC were mostly white males aged 60 to 79 years. Figures 1-4 demonstrates admission growth tendency during the time of the study (Figure-1) and the distributions of these patients according to gender (Figure-2), age group (Figure-3) and ethnicity (Figure-4). The death rate among patients admitted with $\mathrm{BC}$ remained quite stable, being $6.4 \%$ in 2008 and 6.6\% in 2017. Table-1 summarizes BC admissions, deaths and mortality rate.

Figure 1 - Bladder Cancer Admissions on Brazilian Public Health System (2008-2017).

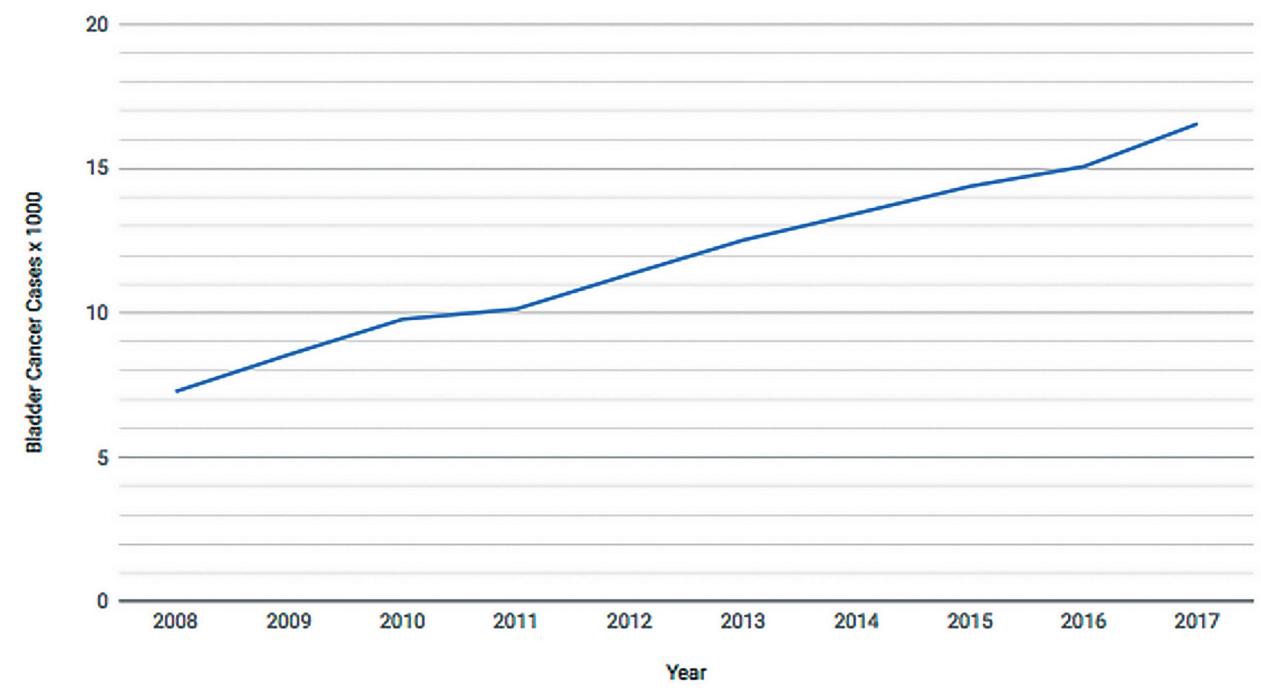

Figure 2 - Bladder Cancer admissions according to gender (2008-2017).

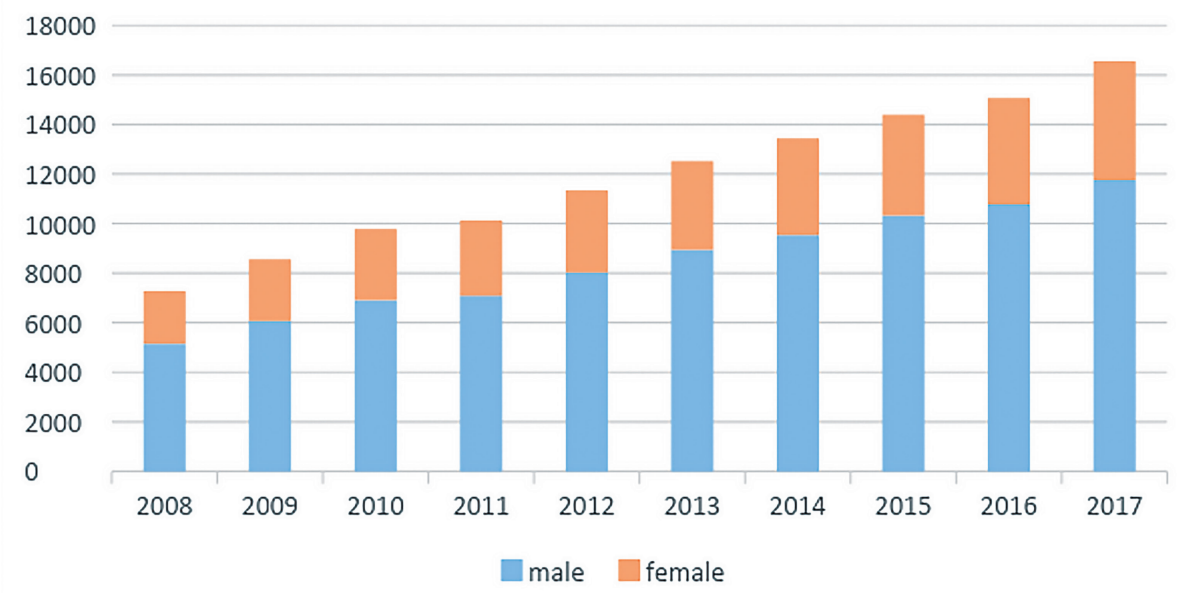


Figure 3 - Bladder Cancer admissions according age group (2008-2017).

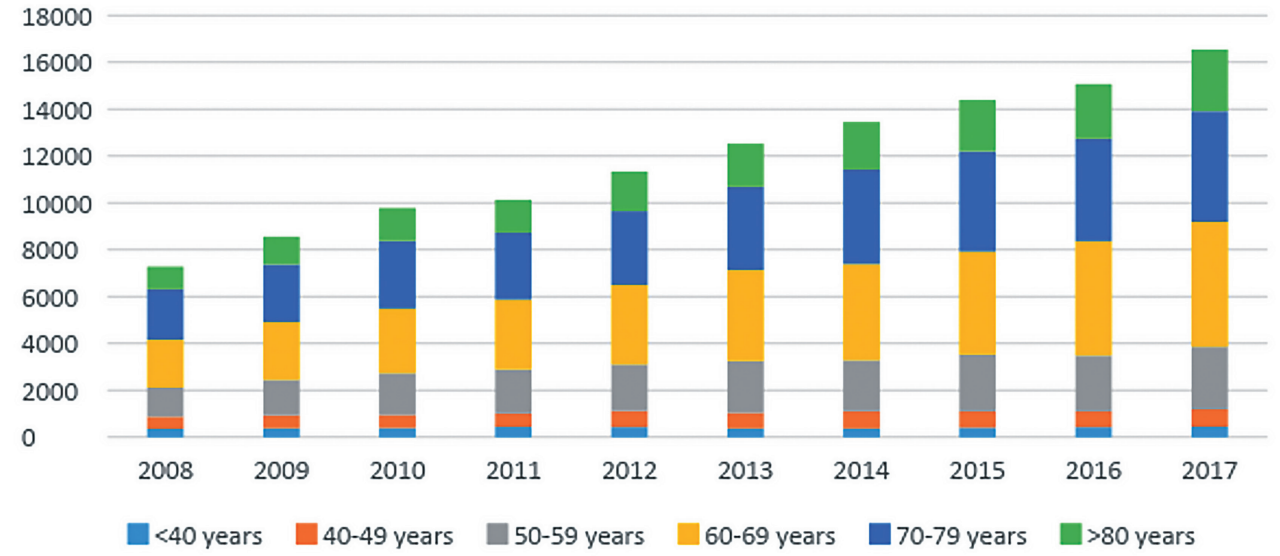

Figure 4 - Bladder Cancer admissions according to ethnicity (2008-2017).

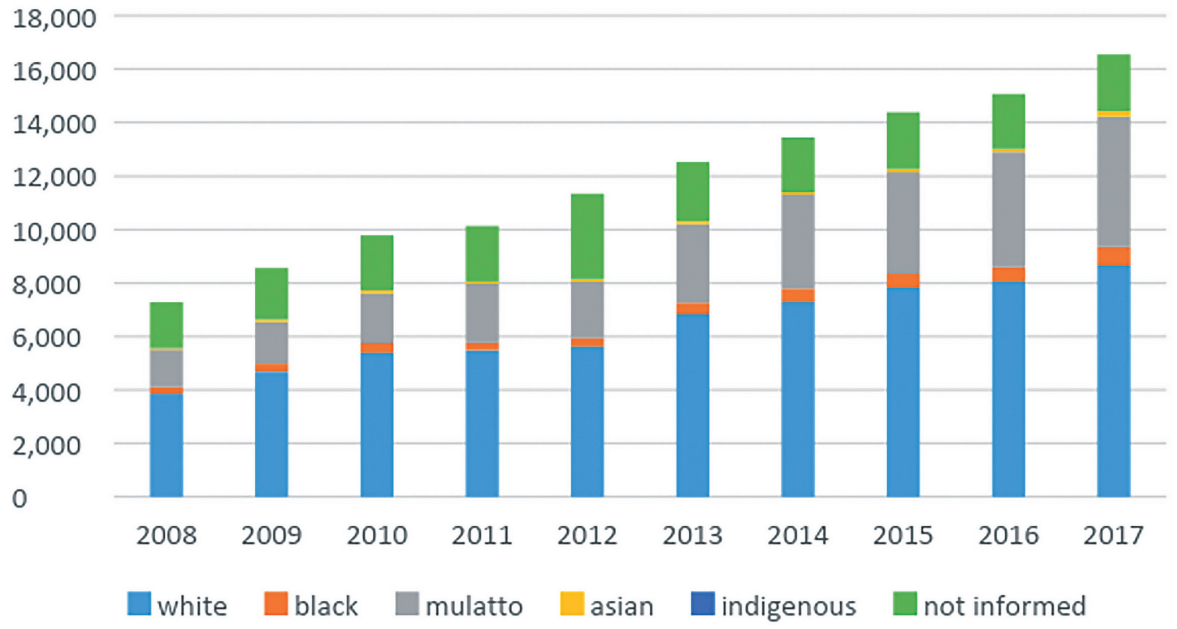

Across the studied years, among individuals who have undergone surgery, there was a $6.75 \%$ mortality rate, being $7.4 \%$ for women and $6.5 \%$ for men. Highest mortality rate occurred in 2008 , when it reached 7.2\% for all individuals and 7.7\% for women along with $7.0 \%$ for men. BC mortality during hospitalization was higher among patients who were over 80 years-old (Figure-5).

During procedure analysis, it was found 77.353 endoscopic procedures to treat BC with 915 deaths and 8.925 open procedures with 441 deaths performed during the decade evaluated, which translates to a mortality rate of $1.2 \%$ and 5.0\%, respectively, between 2008-2017 (Table-2). There were 54.759 elective transurethral bladder resections (TURb) during the studied period, with 326 documented deaths, while there were 589 deaths among the 22.595 urgent TURb, corresponding respectively, to a mortality rate of $0.6 \%$ and $2.6 \%$ (Table-3). Mortality rates for urgent radical cystectomies were about 50\% higher than the rate for elective radical cystectomies (9.74 vs. 6.02).

The open procedures were mostly radical cystectomies, being 1.966 (22.0\%) partial cystec- 
Table 1 - BC Admissions, Deaths and Mortality Rates from 2008-2017.

\begin{tabular}{lccccc}
\hline Year & $\begin{array}{c}\text { Population using Public Health } \\
\text { System }\end{array}$ & $\begin{array}{c}\text { BC cases } \\
(\mathrm{n}=119.058)\end{array}$ & BC rate & BC deaths & Mortality rate \\
\cline { 1 - 3 } 2017 & & & $\left(\times 10^{-5}\right)$ & & $(\%)$ \\
2016 & $162.077,403$ & 16,547 & 10.21 & 1,100 & $6.6 \%$ \\
2015 & $160.022,071$ & 15,069 & 9.42 & 1,032 & $6.8 \%$ \\
2014 & $156.750,009$ & 14,387 & 9.18 & 1,005 & $7.0 \%$ \\
2013 & $154.265,099$ & 13,445 & 8.72 & 879 & $6.5 \%$ \\
2012 & $153.223,204$ & 12,521 & 8.17 & 873 & $7.0 \%$ \\
2011 & $152.901,741$ & 11,340 & 7.42 & 762 & $6.7 \%$ \\
2010 & $152.746,237$ & 10,133 & 6.63 & 651 & $6.4 \%$ \\
2009 & $151.858,919$ & 9,781 & 6.44 & 666 & $6.8 \%$ \\
2008 & $153.659,783$ & 8,558 & 5.57 & 615 & $7.2 \%$ \\
\hline
\end{tabular}

Figure 5 - Bladder Cancer Mortality during hospitalization according to age group.

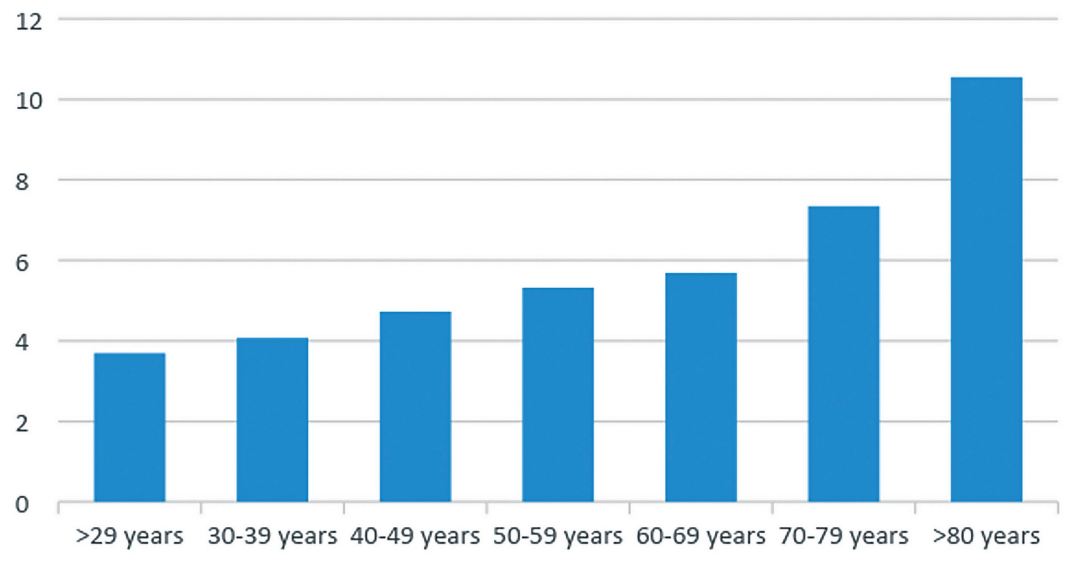

tomies. About 4.209 (47.2\%) of the open procedures were performed in Brazilian Southeast Region, followed by South, Northeast, Midwest and North regions with 1.935 (21.7\%), 1.403 (15.7\%), 742 (8.3\%) and $636(7.1 \%)$ of these surgeries, respectively.

Mean length of hospital stay after was 6.9 days for partial cystectomies and 13.6 days for radical cystectomies. Patients who have undergone surgeries in North Region presented the lowest mean hospital stay of 10.3 days followed by patients from South (11.11), Northeast (12.07), Midwest (12.82) and Southeast (13.27) regions, respectively. For TURb, mean length of hospital stay was of 4.3 days.

During the decade evaluated, the correlation between radical cystectomy and TURb (C/T ratio) presented a significant reduction. In 2008, the C/T ratio was 0.19 , while in 2012 it reduced to 0.11 and then to 0.08 in 2017 (Figure-6). 
Table 2 - Endoscopic vs Open Procedures and related Death rates.

\begin{tabular}{|c|c|c|c|c|c|c|}
\hline \multirow[b]{2}{*}{ Year } & \multicolumn{3}{|c|}{ TURB } & \multicolumn{3}{|c|}{ Radical Cystectomies } \\
\hline & Cases & Deaths & Rate & Cases & Deaths & Rate \\
\hline 2008 & 5,495 & 72 & $1.31 \%$ & 1,053 & 38 & $3.61 \%$ \\
\hline 2009 & 5,814 & 67 & $1.15 \%$ & 1,099 & 52 & $4.73 \%$ \\
\hline 2010 & 6,313 & 62 & $0.98 \%$ & 982 & 41 & $4.18 \%$ \\
\hline 2011 & 6,632 & 62 & $0.93 \%$ & 875 & 42 & $4.80 \%$ \\
\hline 2012 & 7,053 & 96 & $1.36 \%$ & 795 & 43 & $5.41 \%$ \\
\hline 2013 & 8,205 & 109 & $1.33 \%$ & 883 & 47 & $5.32 \%$ \\
\hline 2014 & 8,836 & 117 & $1.32 \%$ & 858 & 54 & $6.29 \%$ \\
\hline 2015 & 9,028 & 120 & $1.33 \%$ & 800 & 37 & $4.63 \%$ \\
\hline 2016 & 9,496 & 99 & $1.04 \%$ & 730 & 33 & $4.52 \%$ \\
\hline 2017 & 10,481 & 111 & $1.06 \%$ & 850 & 54 & $6.35 \%$ \\
\hline Total & 77,353 & 915 & $1.18 \%$ & 8,925 & 441 & $4.98 \%$ \\
\hline
\end{tabular}

Table 3 - Deaths after TURb, elective vs. urgent.

\begin{tabular}{ccccccc}
\hline \multicolumn{7}{c}{ Deaths after TURb (elective vs urgent) } \\
& \multicolumn{7}{c}{ Elective } & & Urgent & \\
\cline { 2 - 6 } & Surgeries & Deaths & Rate (\%) & Surgeries & Deaths & Rate (\%) \\
\hline 2008 & 3,627 & 29 & 0.8 & 1,868 & 43 & 2.3 \\
2009 & 3,950 & 27 & 0.684 & 1,864 & 40 & 2.15 \\
2010 & 4,416 & 22 & 0.498 & 1,897 & 40 & 2.1 \\
2011 & 4,720 & 19 & 0.403 & 1,912 & 43 & 2.24 \\
2012 & 5,026 & 29 & 0.577 & 2,027 & 67 & 3.3 \\
2013 & 5,954 & 47 & 0.789 & 2,251 & 62 & 2.8 \\
2014 & 6,309 & 43 & 0.682 & 2,527 & 74 & 2.9 \\
2015 & 6,382 & 37 & 0.58 & 2,646 & 83 & 3.1 \\
2016 & 6,850 & 32 & 0.467 & 2,646 & 67 & 2.5 \\
2017 & 7,525 & 41 & 0.545 & 2,956 & 70 & 2.36 \\
\hline Total & $\mathbf{5 4 , 7 5 9}$ & $\mathbf{3 2 6}$ & $\mathbf{0 . 5 9 5}$ & $\mathbf{2 2 , 5 9 4}$ & $\mathbf{5 8 9}$ & $\mathbf{2 . 6}$
\end{tabular}


Figure 6 - Cystectomy over TURb Rate from 2008 - 2017.

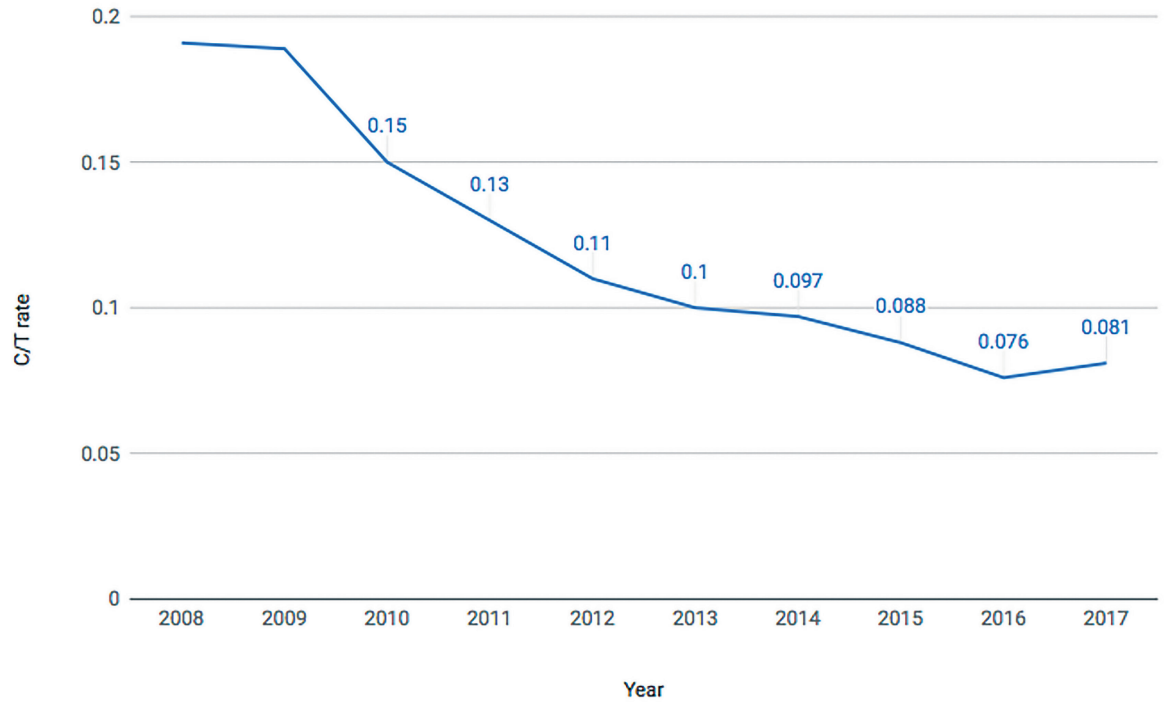

\section{DISCUSSION}

Recent studies have reported that worldwide BC incidence trends towards stabilization or decline in men versus increase in women with an overall decrease in mortality. In Brazil there is paucity of data, but Antonini et al. demonstrated similar trends regarding incidence whilst there was a slightly increase in mortality (14). Our study has some important findings.

First, during the studied decade the number of hospital admissions related to BC has significantly increased. There were 7.277 admissions in 2008 and in 201716.547 were recorded. Even though this finding could be attributed to an increase in BC incidence, it is our belief that better access to health systems and better notification also explains this increment. There are some findings that reinforce the latter hypothesis. Although there was a large number of admissions, death rates among patients admitted with BC related diagnosis remained stable: $6.4 \%$ in 2008 vs. $6.6 \%$ in 2017. Additionally, the number of $\mathrm{BC}$ admissions more than doubled while the number of individuals that rely on Brazilian Public Health System has increased only 6.3\%.

Second, it is important to highlight our findings regarding the $\mathrm{C} / \mathrm{T}$ ratio for $\mathrm{BC}$ treatment. Across the years the $\mathrm{C} / \mathrm{T}$ ratio has decreased from
0.19 in 2008 to 0.08 in 2017. It is our understanding that in an ideal scenario the vast majority of bladder tumors would be treated in early stages by endoscopic procedures. Thus, the $\mathrm{C} / \mathrm{T}$ ratio decrease might point that early diagnosis might have been performed and more superficial $\mathrm{BC}$ cases were treated vis a vis invasive disease. Access to Public Health System might have improved since not only the number of individuals admitted to manage $B C$ has significantly increased but also the proportion of cystectomies has decreased, which, as mentioned before, may reflect an improvement of BC treatment in early stages with TURb. The $\mathrm{C} / \mathrm{T}$ ratio might also reflect regional disparities in Brazil. Over 68\% of the cystectomies were performed in Southeast and South regions; those Brazilian regions present the highest Human Develop Index (HDI) (15). In these southern regions, C/T ratio was lower than that presented in underdeveloped northern regions of the country (Figure-7). This finding might be related to better access to health care along with more equipped hospitals in these regions leading to higher diagnosis rates and adequate treatment. We acknowledge, however, that definite conclusions should not be made regarding the $\mathrm{C} / \mathrm{T}$ ration as this is not a validated index and further studies encompassing different populations and in a more controlled scenario are 
Figure 7 - Cystectomy over TURb Rate from 2008 - 2017 according to geographic regions in Brazil.

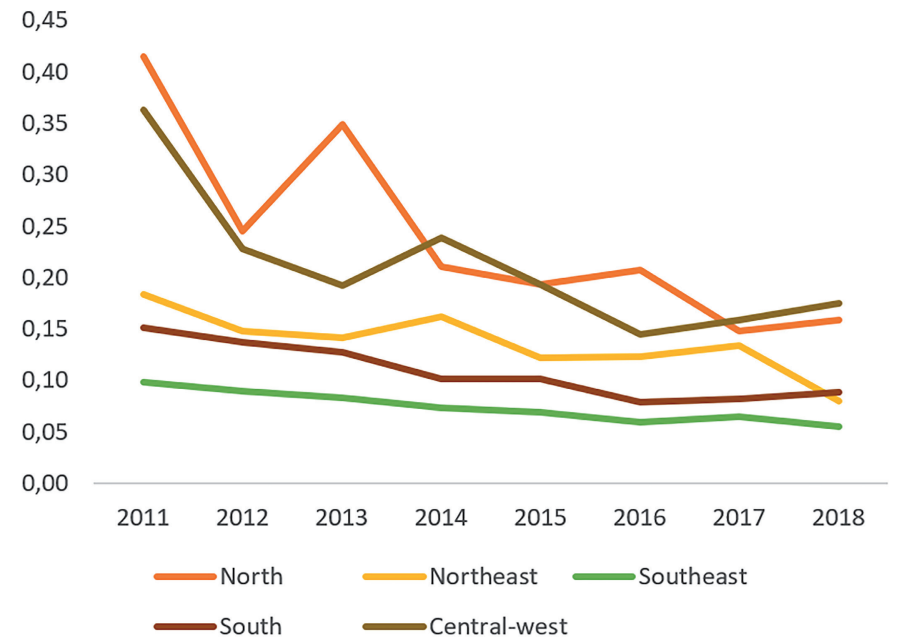

needed to evaluate the usability of the $\mathrm{C} / \mathrm{T}$ ratio as a quality of care index. Figure-7 demonstrates the $\mathrm{C} / \mathrm{T}$ ratio in the five geographic regions of Brazil during the last years.

Third, there were some factors associated with increased mortality following BC treatment. Mortality significantly increased with age (Figure-5), which, according to literature, may reflect late $\mathrm{BC}$ stages at diagnosis and poorer biologic response for both the disease and the morbidity of its treatment (16). This increment in mortality in the elderly population might become progressively more relevant, since we have also observed that population aging process can be translated into a progressively higher number of octogenarians being diagnosed and treated for BC. A large SEER database analysis of over 10.000 patients treated in the US with RC between 1984 and 2004 showed that at 90 days mortality is 1\% for patients younger than 60 years of age, 6\% between ages 69 and 83 and 14\% for patients over age 89 (17).

Cumberbatch et al., at a recent systematic review, reported that mortality varies worldwide but trends to be higher in men than in women (18). According to SEER database, despite 30-day mortality after radical cystectomy was higher for men, 90-day mortality became higher for women (4.8\% Vs. 3.2\%) (17). In accordance, our data, shows higher BC mortality among women vs. men (7.38\% Vs. 6.49\%).
In addition, surgeries performed as an urgent basis burdened a significant higher mortality rate than elective procedures $(2.1 \%$ vs. $0.4 \%, p$ $<0.0001)$. Likewise, higher mortality relative rates occurred following radical cystectomies performed urgently vs. elective (9.74 vs. 6.02, $\mathrm{p}<0.0001$ ). The reported rate of perioperative mortality after radical cystectomy ranges from $0.8 \%$ to $5.6 \%$ in foreign contemporary cystectomy series (17). Mortality rates in the current Brazilian series was somewhat higher than that. Several variables may affect this rate, including patient age, nutrition status, tumor characteristics/advanced stages at diagnosis and the lack of large volume centers. This elevated mortality rates after BC treatment in Brazil is still to be studied in detail as several factors might have influence on this finding: from the data acquisition method to problems related to health care access, especially for the poorer living in remote areas of Brazil.

Fourth, partial cystectomies rate was high, representing $22 \%$ of all open procedures. It has been previously demonstrated in the SEER database that while high volume centers perform partial cystectomies in $12 \%$ of patients, low volume centers tend to perform partial cystectomies in as much as 34\% of all open procedures. These high rates might suggest that many patients are being inadequately treated for their diseases (19).

Our study has some limitations. As an epidemiologic study, definitive conclusions cannot be 
made based exclusively on our findings. Like other neoplasms, BC might still be underreported as cause of hospitalization and death, especially in developing countries as Brazil. Additionally, admissions are not considered in an individual basis, and patients can be considered twice in data analysis. The $\mathrm{C} / \mathrm{T}$ ratio is also not a validated tool and might be biased by several distinctive factors. However, mainly as a result of the difficulty to gather these data, there is a paucity of data of epidemiologic studies in $\mathrm{BC}$ in Brazil. Therefore, our study outlines BC trends in Brazilian population in the last decade and might bring insights to help establish public health policies.

\section{CONCLUSIONS}

In Brazil, $\mathrm{BC}$ incidence seems to corroborate the current literature when it comes to gender and ethnicity. Furthermore, despite BC relatively low incidence, it still represents a significant social economic burden in Brazil, as it presents with recurrent episodes that might require multiple hospitalizations and surgical treatment. Present data might suggest that population access to health care and notification have improved between 2008-2017, with significant growth in the number of hospital admissions related to BC. Considering the impact of BC in Brazilian Public Health system, our data reinforces the importance of further studies and policies on BC risk factors and treatment.

\section{CONFLICT OF INTEREST}

None declared.

\section{REFERENCES}

1. Cancer Facts \& Figures 2018, American Cancer of Society 2018. Avalable at. <https://www.cancer.org/research/ cancer-facts-statistics/all-cancer-facts-figures/cancer-factsfigures-2018.html>. Access on January 2019.

2. SEER Cancer Stat Facts: Bladder Cancer. National Cancer Institute. Avalable at.<https://seer.cancer.gov/statfacts/html/ urinb.html>

3. Bray F, Ferlay J, Soerjomataram I, Siegel RL, Torre LA, Jemal A. Global cancer statistics 2018: GLOBOCAN estimates of incidence and mortality worldwide for 36 cancers in 185 countries. CA Cancer J Clin. 2018;68:394-424.
4. MINISTÉRIO DA SAÚDE- MS. Instituto Nacional de Câncer, Brasil, 2018. Estimativa da Incidência e Mortalidade por Câncer no Brasil - 2018. Avalable at. <http://www1.inca. gov.br/estimativa/2018/casos-taxas-brasil.asp>. Access on March 16, 2019.

5. Scosyrev E, Noyes K, Feng C, Messing E. Sex and racial differences in bladder cancer presentation and mortality in the US. Cancer. 2009;115:68-74.

6. MP Rosim, FM Sarti, B Riveros, GO Pedro, RC Lucchetta, LM Okumura, et al. Estimation of Total Burden of Bladder Cancer in Brazil - An Economic and Clinical Approach. 2018, 21, S26.

7. Jemal A, Siegel R, Xu J, Ward E. Cancer statistics, 2010. CA Cancer J Clin. 2010;60:277-300. Erratum in: CA Cancer J Clin. 2011;61:133-4.

8. Pelucchi C, Bosetti C, Negri E, Malvezzi M, La Vecchia C. Mechanisms of disease: The epidemiology of bladder cancer. Nat Clin Pract Urol. 2006;3:327-40.

9. Nieder AM, John S, Messina CR, Granek IA, Adler HL. Are patients aware of the association between smoking and bladder cancer? J Urol. 2006;176(6 Pt 1):2405-8.

10. Korkes F, Juliano CA, Bunduky MA, Costa AC, Castro $M G$. Amount of tobacco consumption is associated with superficial bladder cancer progression. Einstein (Sao Paulo). 2010;8:473-6

11. Jung I, Messing E. Molecular mechanisms and pathways in bladder cancer development and progression. Cancer Control. 2000;7:325-34.

12. Kogevinas M, 't Mannetje A, Cordier S, Ranft U, González CA, Vineis $P$, et al. Occupation and bladder cancer among men in Western Europe. Cancer Causes Control. 2003;14:907-14.

13. Cha JD, Lourenço DB, Korkes F. Analysis of the association between bladder carcinoma and arsenic concentration in soi and water in southeast Brazil. Int Braz J Urol. 2018;44:906-13.

14. Antoni S, Ferlay J, Soerjomataram I, Znaor A, Jemal A, Bray F. Bladder Cancer Incidence and Mortality: A Global Overview and Recent Trends. Eur Urol. 2017;71:96-108.

15. Atlas do Desenvolvimento Humano do Brasil - IPEA. Avalable at. <http://www.atlasbrasil.org.br/2013/>. Accessed on may 2018.

16. Nielsen ME, Shariat SF, Karakiewicz PI, Lotan Y, Rogers CG, Amiel GE, et al. Advanced age is associated with poorer bladder cancer-specific survival in patients treated with radical cystectomy. Eur Urol. 2007:51:699-706.

17. Isbarn H, Jeldres C, Zini L, Perrotte P, Baillargeon-Gagne $S$, Capitanio $U$, et al. A population based assessment of perioperative mortality after cystectomy for bladder cancer. J Urol. 2009;182:70-7. 
18. Cumberbatch MGK, Jubber I, Black PC, Esperto F, Figueroa JD, Kamat AM, et al. Epidemiology of Bladder Cancer: A Systematic Review and Contemporary Update of Risk Factors in 2018. Eur Urol. 2018;74:784-795.

19. Hollenbeck BK, Wei Y, Birkmeyer JD. Volume, process of care, and operative mortality for cystectomy for bladder cancer. Urology. 2007;69:871-5.
Correspondence address:

Frederico Timoteo Silva Cunha, MD

Faculdade de Medicina do ABC

Rua Lauro Gomes, n 2000

Santo Andre, São Paulo, 09060-650, Brasil

E-mail: fred.timoteo@gmail.com 